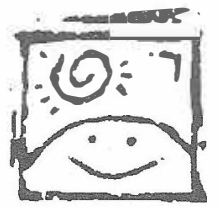

http://doi.org/10.15359/ree.2004-5.6

Educación Inicial

\title{
EL DIBUJO COMO PRIMERA ESCRITURA DEL NIÑO
}

\author{
$M^{a}$ del Rosario Vargas León*
}

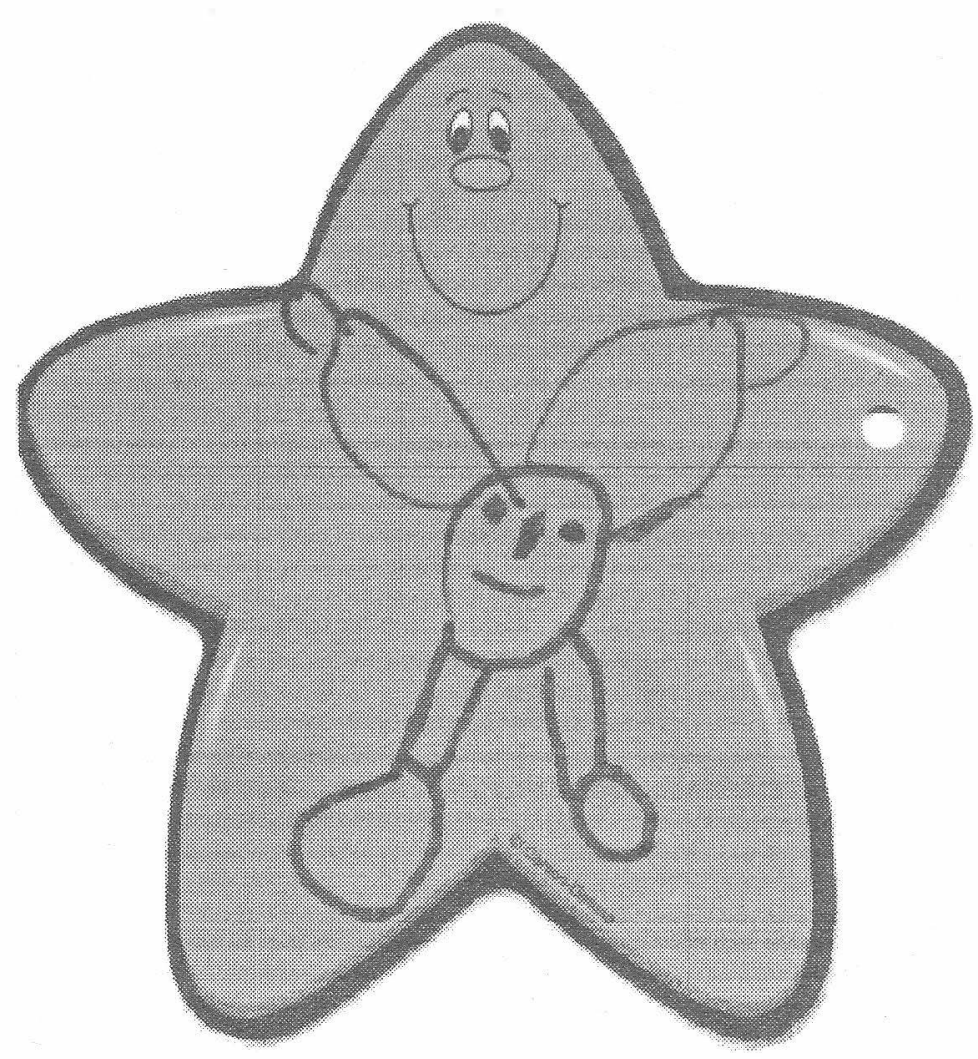

* Profesora de Artes Plásticas y Bachiller en Artes Plásticas con énfasis en Artes Gráficas. de la Universidad de Costa Rica. Licenciada en Ciencias de la Educación con especialidad en Administración Educativa de la Universidad Nacional.

Se ha desempeñado como profesora, investigadora y extensionista en la División de Educación Básica del CIDE en la Universidad Nacional. Actualmente coordina el proyecto de extensión Implementación de una didáctica constructivista en los procesos iniciales de lectura y escritura. 
En el siguiente trabajo, se aborda un aspecto muy poco tomado en cuenta en el proceso de enseñanza y aprendizaje de la lectura y la escritura, como lo es la simbolización gráfica o dibujo del niño.

Diversas investigaciones a nivel internacional y nacional demuestran que el dibujo, por ser un componente de la génesis del niño, se constituve en un aspecto medular en la construcción que él realiza de su lectura y escritura inicial.

El niñopuede convertir el dibujo en un sistema de comunicación muv efectivo. El proceso creativo que lo lleva a enfrentar constantemente conflictos cognitivos para inventar y reinventa. formas de expresión cada vez más comunicativas lo irá preparando para entender y comprender mejor el sistema alfabético convencional que su medio cultural y social le impone.

La experiencia realizada en dos escuelas costarricenses, desde el Provecto de Extensión Implementación de una didáctica constructivista en los procesos iniciales de lectura y escritura, de la División de Educación Básica del CIDE, de la Universidad Nacional, ha demostrado que al tomar en cuenta la génesis de la construcción del conocimiento del niño, respeta y promueve sus formas de expresión simbólica hace que el aprendizaje de la lectura y. escritura sea más significativo para el niño.

\section{Introducción}

Desde tiempos prehistóricos, el dibujo ha desempeñado un importante papel en la evolución de los sistemas de comunicación de la humanidad. El dibujo es la primera forma de expresión gráfica del niño, a partir de la cual puede comunicar sus pensamientos, sus sentimientos y su conocimiento del mundo que lo rodea. Es un lenguaje, el niño al dibujar habla consigo mismo y con su mundo externo, muchas cosas que él nunca podrá expresar con palabras es posible que las manifieste mediante dibujos.

El niño desde el momento en que comienza a experimentar el efecto del desplazamiento de una crayola. de un lápiz, o de cualquier otro instrumento que deje huellas sobre el papel, inicia su proceso de simbolización gráfica.

Al respecto, García ( 2003) expresa que:

\begin{abstract}
"Cuando se habla de simbolización gráfica en el niño, se refiere a la creación de imágenes que ponen en relación sus sentimientos, sus vivencias íntimas, aquellas que están sufriendo influencia de todo lo acumulado por la cultura del hombre" (p.71).
\end{abstract}

En ese sentido, la línea espontánea de sus garabatos y los círculos abiertos y cortados, se convierten en el soporte de sus "primeros ideogramas". El ideograma corresponde a una etapa genética importante porque manifiesta el poder que tiene el niño de inventar formas gráficas que simbolicen sus ideas y se constituyen en el "primer alfabeto" primitivo del niño (Luçart citado por Fortuny 1980).

Conforme evolucionan esas formas gráficas se producen más posibilidades de combinación y cada forma irá cambiando de significado de acuerdo a la realidad que represente. A medida que los niños se ejercitan en el dibujo, trazos harán más representativos, y llegarán a ser capaces de simbolizar sobre el 
papel no solo las cosas que perciben directamente de la realidad, sino también de situaciones dinámicas como el movimiento: realidades no perceptibles como el viento. Los sonidos. y de esta manera, irán haciendo más expresivo y comunicativo su dibujo.

Leal y Fortuny consideran los recursos gráficos inventados por los niños para representar aquellas situaciones que no son perceptibles directamente "mencionadas anteriormente, como los inicios del camino hacia la adquisición de los signos convencionales de la lengua escrita. De acuerdo con estas autoras, "el paso del dibujo estudiado como símbolo a la escritura entendida como sistema de signos no se realiza de forma brusca, sino por el contrario sigue un lento proceso". (Leal y Fortuny 1985, p. 238).

Se puede inferir que del mismo modo que se da un proceso de construcción del lenguaje oral, se dará igualmente un proceso con el grafismo como representación simbólica, como signo arbitrario convencional, es decir, entre el dibujo y la escritura. Debe pasar mucho tiempo antes de que el niño utilice el lenguaje escrito como sustituto total de otros sistemas que le son más conocidos como son el lenguaje oral y el dibujo.

Por lo general el niño pequeño considera que el dibujo y no las palabras es lo que hace más comprensible lo que quiere expresar.

Aurora Leal (1987) menciona que:

"La sociedad adulta tiene el máximo interés en enseñar a leer y a escribir a los niños desde una edad muy temprana, pero en general ese mundo adulto no suele llegar a enterarse de cómo esos niños entienden lo que se les intenta hacer comprender con tanto esfuerzo, ni de lo que piensan cuando están solos, ni de las cosas que se les ocurren ante la 
abrumadora presencia de esas manchas negras en libros y carteles. Si estos pensamientos infantiles son poco conocidos para el adulto lo son mucho menos los sistemas que los niños pueden inventar para construir por sí mismos formas comunicables de simbolización" (p.189).

La escuela impone al niño un modelo de escritura convencional, el cual debe imitar, aunque no lo comprenda ni tenga significado para él. Esto limita su potencial para crear un sistema de comunicación gráfica por sí mismo. Sin embargo, en su vida cotidiana, los niños inventan modelos de comunicación oral y gráfica y es frecuente que entre grupos de amiguitos establezcan su propio código de comunicación con el fin de no ser entendidos por otros compañeros, lo mismo sucede con los niños que inventan su propio sistema de escritura para que sus notas personales no sean entendidas por nadie.

\section{El dibujo y sus aspectos convencionales}

Leal (1997) manifiesta que el dibujar una idea supone una interpretación personal de la misma, que además debe traducirse y reflejarse en el papel. Este producto gráfico tiene características muy subjetivas, propias de la interpretación de quien lo hizo, quien le da además su propio significado. Pero que, una vez que está sobre el papel, debe ser interpretado por el receptor o lector del dibujo con el mismo sentido que le dio el autor.

El promover en los niños la motivación de expresar sus ideas en el dibujo lo mejor posible, de manera que su mensaje sea comprendido por quienes interpreten el dibujo, lo irá preparando para entender los aspectos convencionales de la lengua escrita.

\section{El dibujo en el desarrollo de la lectura y escritura del niño preescolar}

Desde el proyecto de Extensión Implementación de una didáctica constructivista en los procesos iniciales de lectura y escritura, perteneciente a la División de Educación Básica del CIDE, de la Universidad Nacional, cuyo propósito es coadyuvar al mejoramiento de la calidad de la educación costarricense a partir de la capacitación y actualización de docentes en servicio, en innovaciones pedagógicas constructivistas para el proceso de enseñanza y aprendizaje de la lectura y escritura inicial. De esta forma se ha logrado aplicar en las aulas una experiencia didáctica en la que se le da mucha importancia al dibujo como primera forma de comunicación gráfica y como representación del pensamiento del niño que inicia el aprendizaje de la lectura y escritura. 
Esta didáctica se fundamenta en la idea de que el niño al estar en contacto con un sistema de comunicación gráfica en un ambiente alfabetizado, es capaz de producir su propia simbolización, que recurre principalmente al dibujo. Según García ( 2003): “ simbolizar es utilizar por analogía la representación de una cosa por otra a merced de alguna relación de semejanza entre ellas. Simbolizar es crear símbolos: y el símbolo es un acto creativo" (p. 71). Desde esta perspectiva el niño es capaz de producir en forma individual y grupal un sistema de simbolización que le permite la comunicación , constituyéndose estas experiencias en las etapas previas para la adquisición de los signos convencionales de la lengua escrita y estableciéndose, de esta manera, una continuidad entre el dibujo y la escritura.

Al propiciar la creación de un sistema de simbolización gráfica mediante el dibujo, el aprendizaje de la lengua escrita no queda reducido a la adquisición mecánica de los signos alfabéticos carentes de significación, sino que su construcción ubica al niño en un marco más amplio de posibilidades intelectuales de elaboración. Esto lo lleva a reflexionar sobre las leyes del sistema alfabético, su aplicación y adaptación acorde a sus necesidades de comunicación gráfica (Leal 1997).

Es importante destacar que al igual que el niño construye su lenguaje oral. inventando y experimentando formas de expresión, también se le debe permitir un proceso constructivo de la lengua escrita a partir de sus representaciones simbólicas que son regidas por sus propias normas, aunque no correspondan todavía a las normas convencionales.

Así, por ejemplo, desde esta didáctica constructivista se propone que los niños en edad preescolar para representar su nombre confeccionen dibujos que se constituyen en códigos personales o individuales, los cuales en un principio serán entendidos solo por sus autores; con ellos identifican sus pertenencias, los trabajos que realizan en el aula, elaboran un gafete y una tarjeta que la docente utiliza para pasar lista. Esta es una actividad que se aplica antes de aportar a los niños la escritura alfabética del nombre propio; de esta manera, se evita que el niño que ingresa a preescolar dibuje su nombre sin comprender todavía los signos del sistema alfabético convencional.

Es requisito indispensable que este código personal se mantenga estable, es decir, el niño debe tratar de hacer siempre el mismo dibujo en cada una de las opciones en que lo va a emplear. Por consiguiente, los niños se van apropiando de una de las primeras leyes del código escrito que es la estabilidad. El siguiente es un ejemplo de un código

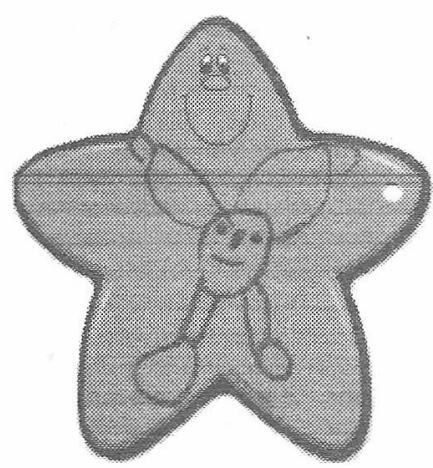


individual o personal de un niño de preescolar de la Escuela Ramón Barrantes. que representa su nombre propio en un gafete.

Este código individual poco a poco se va convirtiendo en un código colectivo, porque rápidamente los niños identifican los códigos personales de sus compañeros. Es entonces cuando se proponen otras situaciones de comunicación gráfica, donde individualmente o en grupo de ellos elaboren un dibujo que comunique una idea o un mensaje, como por ejemplo: dibujar las diferentes opciones para elegir el tema a estudiar. dibujar lo que se aprendió del tema en estudio, elaborar consignas, identificar las diferentes áreas de trabajo del aula, enviar mensajes al hogar, representar los ingredientes y los pasos a seguir para elaborar recetas de cocina, crear cuentos; y en actividades de lectura creativa, como por ejemplo, dibujar los personajes, enviar una carta a un personaje, ilustrar lo que más le gustó o lo que le disgustó de un cuento, dibujarle un nuevo final, entre otras.

Con estas actividades se genera el llamado código colectivo, el cual requiere que el niño tome conciencia de la necesidad de elegir el uso de un mismo dibujo. es decir un mismo código como medio de comunicación, ya que el uso de los códigos personales impide la transmisión de mensajes al resto del grupo.

\section{Ventajas del código colectivo}

De la experiencia del uso del código colectivo se deriva una fase del dibujo infantil que Fortuny (1987) llama el "dibujo con intención". Esta forma de dibujo trasciende el dibujo libre de recreación, ya que al estarse utilizando como un sistema gráfico de comunicación demanda del niño una mejor organización de su pensamiento, así como la selección de los elementos idóneos para representarlos gráficamente y poder lograr comunicar mejor su idea. Esta situación lo lleva a analizar sus propios errores de expresión gráfica y a modificarla constantemente con el fin de lograr una comunicación efectiva.

También, el dibujo con intención requiere que se enfaticen los detalles y que se incluyan elementos que son clave para la comunicación del mensaje, lo que beneficia la concentración y la observación, como procesos esenciales en el aprendizaje de la lectura y la escritura.

Asimismo, por estar empleando un sistema de simbolización, los niños deben apoyar su mensaje "escrito mediante el dibujo", con el lenguaje oral, lo que les facilita establecer relaciones entre el lenguaje oral y el lenguaje escrito, que fortalece la relación pensamiento-lenguaje, pues debe darse una lógica y coherente organización de las ideas a comunicar, también, se propicia el enriquecimiento del vocabulario y la ejercitación de la memoria. 
Con la elaboración de códigos colectivos el niño accede a la ley de la convencionalidad e incluso a la de la arbitrariedad del sistema alfabético, pues debe, mediante una negociación con sus compañeros, decidir cuál dibujo comunica mejor la idea que se representa y aceptar ese dibujo como portador del mensaje que todos van a entender por igual dentro del contexto en que se encuentren.

Los siguientes son ejemplos de códigos colectivos, elaborados por niños de preescolar de la escuela España, y de la escuela Ramón Barrantes:
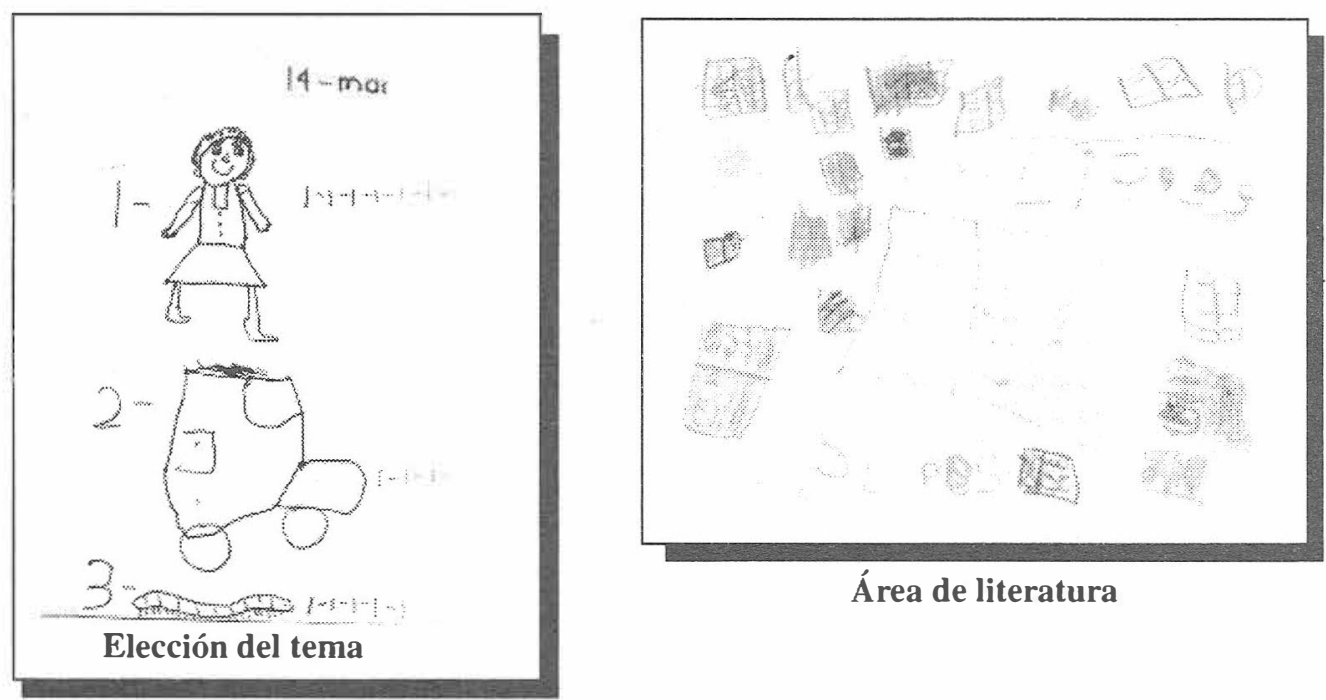

Área de literatura
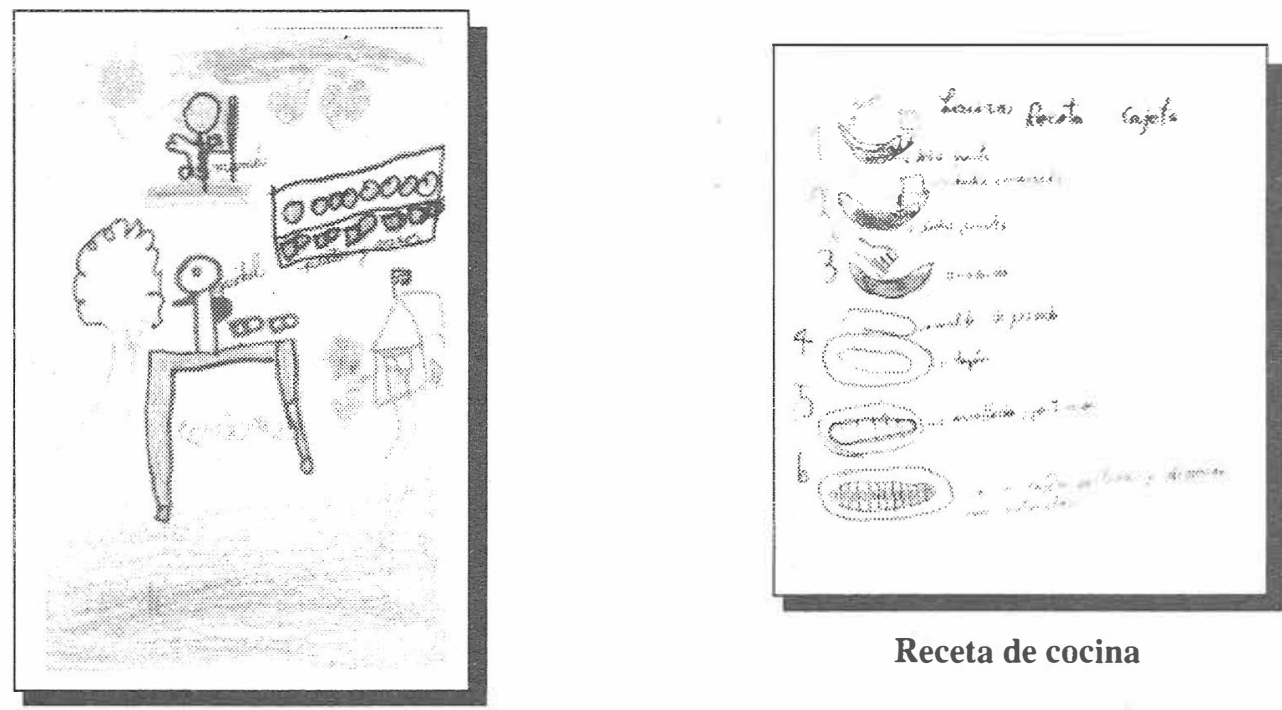

Receta de cocina

Invitación a reunión 
Las anteriores son algunas de las posibilidades de simbolización que inicialmente puede emplear el niño para comunicarse, y en las cuales se evidencia el esfuerzo cognitivo que han tenido que desarollar los niños para elaborarlos, pues en cada una de esas simbolizaciones podemos encontrar elementos semejantes a los reales, que han sido dibujados con la plena intencionalidad de comunicación. Cada elemento dibujado podría sustituirse por una " palabra escrita”. Observemos solo una de estas representaciones simbólicas, por ejemplo, la invitación a una reunión: a la derecha está representada la escuela, caracterizada por la bandera, en la parte superior aparece la figura femenina que representa la madre que por lo general es la persona que asiste a las reuniones, además, se incluye un aspecto muy significativo para el niño, como lo es el refrigerio, que se suele brindar en esas reuniones. En esos " símbolos" está contenido todo el mensaje a comunicar al hogar. Lo complementan otras representaciones propias de la etapa de expresión plástica, la etapa preesquemática en la que se encuentra el niño, como lo son elementos del paisaje.

Poco a poco el niño irá modificando sus planteamientos dando lugar a nuevas formas de interpretación en su proceso evolutivo de apropiación del sistema alfabético convencional. Es común observar cómo los niños incursionan en el uso de letras y seudoletras (todavía simbólicamente) para complementar o ampliar el mensaje de su dibujo.

Ferreiro y Teberosky (1979) abordan el estudio de la apropiación de la lengua escrita en el niño, en el que analizan una serie de hipótesis que ellos se plantean al intentar diferenciar el dibujo de la escritura y entre la imagen y el texto.

De acuerdo con la teoría psicogenética propuesta por estas autoras, los primeros conflictos cognitivos que el niño enfrenta comienzan por considerar que la escritura conlleva algunas propiedades del objeto que representan, al igual que el dibujo, la escritura representa para el niño el contenido del mensaje, a este nivel se le denomina concreto. En este nivel el niño no diferencia entre dibujo y escritura, para él significan lo mismo.

Más adelante los niños comienzan a analizar las propiedades de la lengua escrita, a esta fase se le denomina nivel simbólico o presilábico, en la que empiezan a relacionar la escritura con el concepto que tienen del objeto. Así, por ejemplo, los niños de corta edad opinan que a los objetos grandes les corresponde una escritura proporcional a su tamaño.

Para estos niños los textos pueden representar nombres de los objetos, y esta interpretación se denomina: hipótesis del nombre. También construyen las hipótesis de cantidad y la de variedad de las grafías, como condiciones necesarias para que el escrito se pueda leer. Para el niño si un escrito tiene pocas letras o todas son iguales, no puede significar nada. 
En una etapa posterior el niño se plantea un nuevo problema, el de la relación sonora del habla, y piensa que en la escritura es necesario hacer corresponder la letra con cada símbolo emitido; esta conceptualización corresponde a un nivel lingüístico y se denomina hipótesis silábica.

Cuando el niño trata de identificar los textos del medio en que se desenvuelve, su hipótesis silábica no le es suficiente y debe construir una nueva hipótesis que le perrnita comprender las características alfabéticas de nuestro sistema de escritura y establecer así una correspondencia entre los fonemas que forman una palabra y las letras necesarias para escribirla accediendo al nivel alfabético.

De los estudios de Ferreiro y Teberosky se concluye que el niño inicia su aprendizaje de la escritura mucho antes de que el adulto inicie una enseñanza sistemática de la misma y que trata de entender desde muy temprano toda la información que el ambiente alfabetizado le proporciona: rótulos, anuncios, textos en los envases, etiquetas en las prendas de vestir, periódicos, revistas, televisión, etc.

\section{La literatura infantil como un medio de promover la expresión gráfica del niño preescolar}

Para el abordaje de la literatura infantil en el preescolar, esta didáctica constructivista propone la aplicación de actividades de lectura creativa, comouna forma de desarrollar la competencia linguiística y comunicativa de los niños y la producción de textos narrativos a partir del dibujo. Se enfatiza en primer lugar la expresión oral de relatos cotidianos acerca de las propias vivencias, como una forma de favorecer la organización del pensamiento del niño, en los distintos momentos de la historia o sucesos naturales para ser expresados oralmente.

La narración de cuentos y leyendas por parte de la docente favorece que los niños vayan construyendo una idea de cómo es la organización temporal y casua! de los hechos en un cuento, y les permite analizar sus partes; los cuentos tienen un inicio, generailmente una entrada típica ("Había una vez"... o "Hace muchos años"...), un desarrollo, donde se plantea el problema, una resolución y regularmente un cierre que también puede ser típico: "Colorín colorado, este cuento se ha acabado".

Una vez que los niños han escuchado la narración por parte de la docente, se promueve que se reelabore oralmente el cuento, o partes de él, y luego que cada niño lo haga en forma dibujada. En ese proceso generalmente agregan letras o seudoletras para representar el texto escrito en el que integran al sistema simbólico sus conceptualizaciones acerca de la escritura, luego narran el cuento en forma oral, a partir de sus dibujos y "escrituras". 
Un ejemplo de la construcción de un final nuevo para un cuento se presenta a continuación:

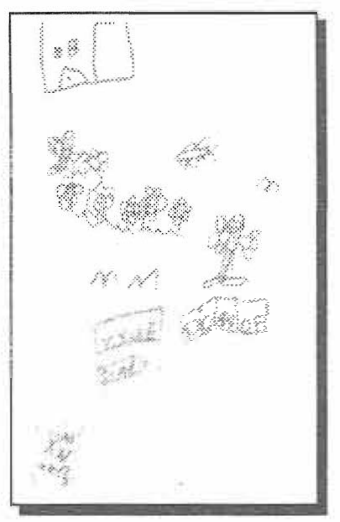

Final nuevo del cuento Uvieta:

"El se encontró con una amiga que estaba contenta y ayudándole a sembrar a Uvieta, porque le dijo a Dios que no iba a volver a ser malo y que por eso le estaba sembrando todas las flores, para que lo perdone".

(Se respeta la expresión oral del niño).

Graves (1983), citado por Vázquez y Matteoda (1994), ha puesto de relieve el papel del dibujo en la composición escrita. Según este autor, el dibujo constituye una etapa de ensayo, un banco de ideas al cual el sujeto recurre para otorgar sustancia a su escritura. Desde este punto de vista, el dibujo ayuda a los niños pequeños, ya que opera como un intermediario entre el lenguaje oral y el escrito.

Los estudios de Graves pusieron en evidencia que el dibujo ayuda también en la elección del tema, de manera que dibujar antes de escribir posibilita a los niños la creación de escenarios para una composición. Esta observación estimula a los niños a reconstruir o inventar un cuento dibujado y que después lo compartan con sus compañeros.

El siguiente es un ejemplo de un cuento colectivo, creado a partir de dibujos por un grupo de niños de preescolar de la Escuela Ramón Barrantes:
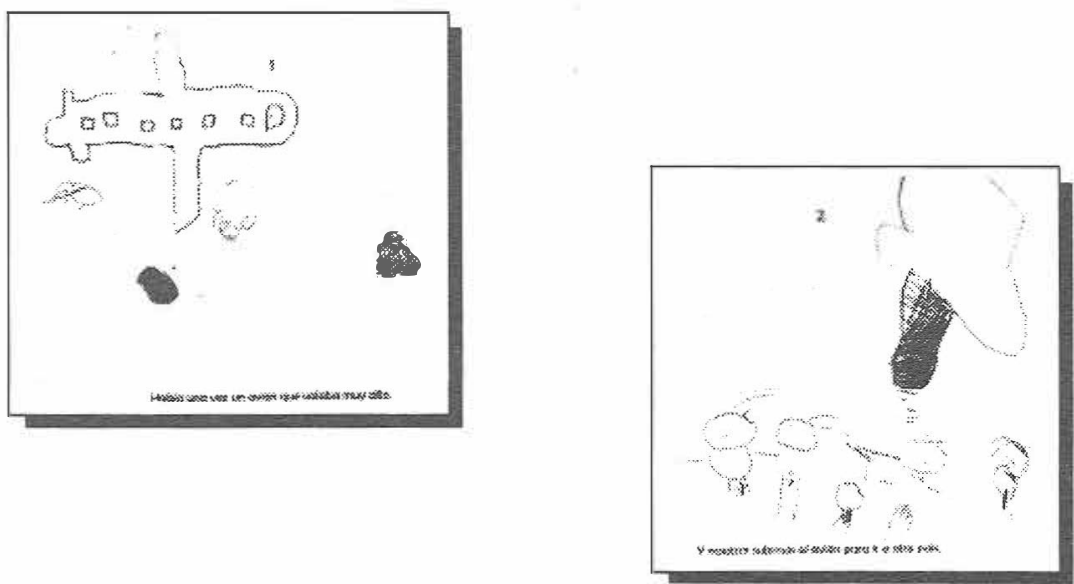

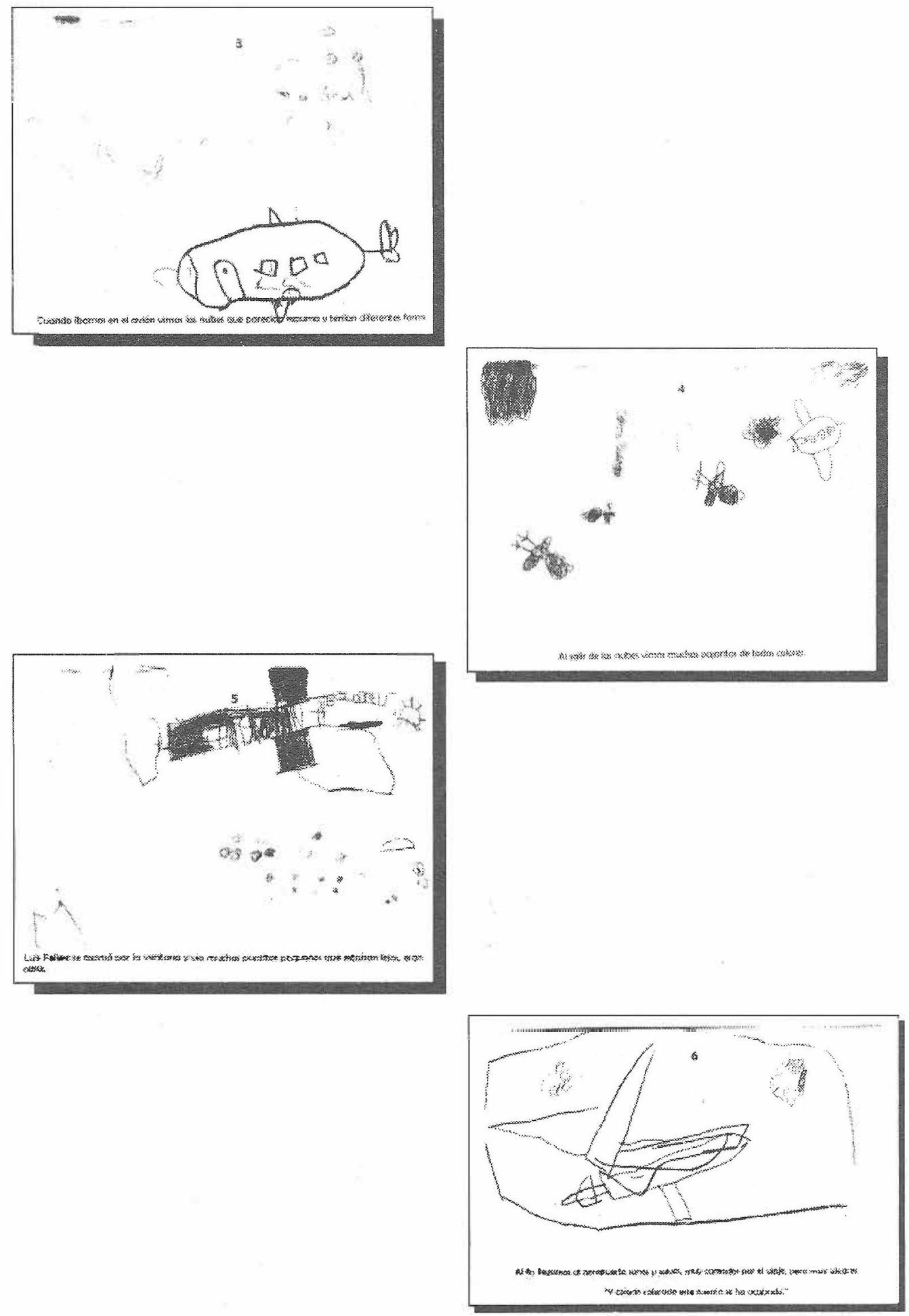
El niño pequeño aplica ambos sistemas de representación: el dibujo y la escritura (con su propias hipótesis ) para darle significado al texto. Lo mismo sucede cuando se les propone que "lean" alguno de los cuentos que existen en el aula, ellos lo hacen transitando fluidamente de un sistema a otro, narran el relato compensando en forma oral las palabras escritas con las ilustraciones; es decir, "arman el relato a partir del dibujo".

En la medida que el niño se apropia del lenguaje escrito para la producción de un relato, el dibujo pasa a ser un sistema equivalente de representación. Se da entonces un nivel más elaborado de producción, en el que se consideran las observaciones de Graves (1983), quien caracteriza como más avanzados a los niños que dibujan después que el texto ha sido escrito con la sola finalidad de ilustrar una escena seleccionada del mismo.

En este nivel los niños son capaces de reflexionar sobre el texto escrito, sin hacer referencia al dibujo. No obstante la presencia del núcleo básico de la estructura narrativa: problema, acciones y resolución, está apenas esbozada. Los niños todavía no son capaces de aplicar el esquema del cuento en el texto escrito, aunque sí se evidencia en el relato oral (Graves citado por Vázquez y Matteoda 1994).

\section{Conclusiones}

Desde una perspectiva constructivista, el aprendizaje de la lengua escrita, debe ser considerado como un proceso natural en el que es el niño el que construye su propio sistema de simbolización gráfica, mediante interacciones entre su creación y el modelo de escritura convencional que recibe de su entorno cultural.

Tomar en cuenta el dibujo como un medio natural de expresión y de comunicación gráfica del niño, para integrarlo al aprendizaje constructivo del sistema alfabético convencional, mejorará notablemente ese aprendizaje y lo hará más significativo porque igualmente, como lo hizo con su sistema simbólico, le permitirá inventar, experimentar y reelaborar su propio sistema de lectura y escritura hasta llegar a apropiarse del sistema convencional y comprender las normas y las leyes que lo rigen, en el que descubrirá día a día sus potencialidades para aprender a comunicarse efectivamente a través de la lectura y escritura.

Estos planteamientos tienen implicaciones pedagógicas, que ameritan un cambio en la concepción de la lectura y escritura como "simples objetos de estudio escolar" y esto requiere el conocimiento de las teorías que sustentan la capacidad temprana que tiene el niño para reconocer la lengua como un importante medio de comunicación de parte de los docentes, desde antes de su ingreso a la educación formal y su capacidad para emplear la "simbolización gráfica" como su primera escritura. 


\section{Referencias}

Ferreiro, E. y Teberosky, A. (1979) Los sistemas de escritura en el desarrollo, del niño. México. Siglo XXI.

Fortuny, J. (1987). La evolución del dibujo. En: Los procesos de lectura y escritura. Selección de lecturas. Heredia. EUNA.

García, J. (2003). Educar para escribir. México. Limusa.

Gómez. M. (1982). La adquisición de la lengua escrita. En: Los procesos de lectura y escritura. Selección de Lecturas. Heredia. EUNA.

Leal, A.(1997). Construcción de sistemas simbólicos. La lengua escrita como creación. Barcelona. GEDISA. Segunda edición.

Leal, A. y Fortuny (1988). Lenguaje. Enciclopedia Práctica Pedagógica. Vol. I y III. Barcelona. Planeta.

Sánchez, M. y Flores, L. (1990). Los procesos de de lectura y escritura. Selección de Lecturas. Heredia.

Vázquez, A. y Matteoda, M. (1994). La estructura narrativa en el discurso escrito infantil: estudio exploratorio. En: Lectura y vida. Revista Latinoamericana de Lectura. Año15, Nº4. Diciembre de 1984. 